\title{
Injection Molding Technology
}

\author{
Dmitry A. Kurasov \\ Kurgan State University, Kurgan region, Kurgan, 640020, Russia \\ naukka@mail.ru
}

Keywords: Injection Molding, Injection Molding Automation, Mold, Plastic, Metal

\begin{abstract}
The injection molding process is one of the most efficient and economical casting processes. The process is becoming increasingly common in various industries in large-scale and mass production of castings. It should be noted that by having great advantages over other methods of obtaining high-quality castings of higher accuracy, injection molding makes it possible to bring the dimensions of the castings as close as possible to the dimensions of the finished parts.
\end{abstract}

\section{Introduction}

The article discusses the injection molding process, the general presentation and its features. The main types of this technology and its classification are considered. Conclusions on positive and negative aspects of each technology are formed. Special attention is paid to the capabilities of mathematical and computer modeling, which allows to ensure control and optimization of the parameters of the injection molding process.

\section{Principle of Injection Molding Process Implementation}

The injection molding process is one of the most efficient and economical casting processes. The process is becoming increasingly common in various industries in large-scale and mass production of castings [1-3]. It should be noted that by having great advantages over other methods of obtaining high-quality castings of higher accuracy, injection molding makes it possible to bring the dimensions of the castings as close as possible to the dimensions of the finished parts.

Injection molding is a very difficult process to control, since a number of manufacturing factors constantly change in the process, on which the quality of the resulting product depends, such as the temperature ratio or injection rate of molten metal, the accuracy of the manufacture of the matrix and its lubrication, and many other dynamically changing factors. In conventional manufacturing, success depends on the experience and qualifications of specialists, sometimes parts require secondary processing to eliminate defects and ensure their compliance with the highest quality standards.

The classic injection molding machine is shown in Fig. 1.

Injection molding is a relatively old technology, it has been used since the late 1800 s. Injection molding was first used by G. Brouss in 1838 in the manufacture of a letter depicting letters for newspaper printing machines. In 1839, the first patent was taken for a piston machine for pouring metal under pressure. In mechanical engineering, injection molding began to be used in 1849 for the production of small parts from tin-lead alloys. The V Sturgis machine used for these purposes had a manual piston drive, with the help of which a pressure of 100-150 Pa was created in the pressing chamber located inside the crucible with molten metal.

In injection molding machines, a huge screw (screw) is installed, which directs molten plastic into the mold under high pressure. This screw transmission method was invented in 1946, and is still used. Injection molding machines are, of course, not the same as modern high-tech 3D printing machines [4]. There is nothing innovative in them, but the use of injection molding is a prerequisite 
for creating most new innovative products. The mold consists of two halves (die and punch), which, when closed, form a cavity in the form of a desired part. Hot liquid plastic is poured into it under high pressure. High pressure is required for the molten plastic to fill each portion in the mold cavity. When the plastic cools, the two mold halves are moved apart, and the finished part is removed from them.

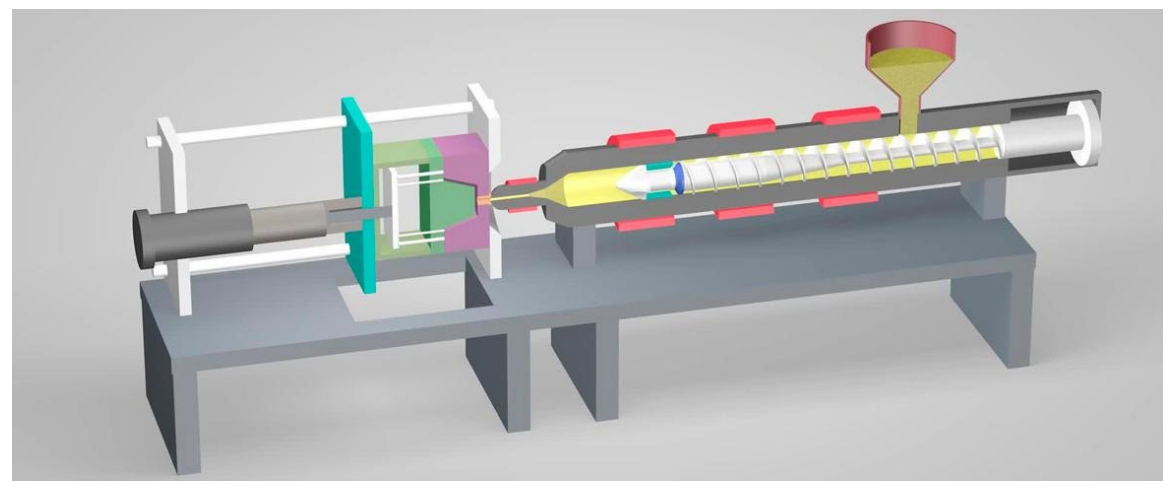

Fig. 1. Machine of Injection Molding

Developing the design and design of the case for mass production is a rather difficult task, and the cost of the molds themselves is in the tens of thousands of dollars. At the same time, injection molding remains one of the most popular technologies, because only it allows you to produce millions of identical parts at an incredibly low price per piece.

The technology of injection molding and high pressure casting is described in the following works [5-7].

\section{Advantages and disadvantages of injection molding technology}

The advantages of the injection molding method include the possibility of obtaining complex thinwalled castings, which are quite difficult to obtain by other casting methods; high physical and mechanical properties of castings due to specific conditions of casting formation; strength characteristics of parts as compared to casting into sand molds increase by $15-20 \%$; obtaining highquality castings with low surface roughness and high dimensional accuracy; high productivity of the process due to minimum casting cycle duration, complex mechanization and automation of the production process; low cost of casting due to reduced labour input for manufacturing parts; ensuring favorable sanitary and hygienic working conditions of workers.

The disadvantages of the injection molding method include: the high cost of molds, the complexity and duration of their manufacture; low resistance of molds, especially at casting of alloys with high melting point (steel, cast iron, copper alloys); difficulty of casting with complex cavities and undercuts; unsuitability of the metal mold, which contributes to the appearance of stresses in castings during cooling; therefore, injection molding alloys must have a narrow crystallization interval, high fluid flow, and sufficient strength and ductility.

As a rule, in Russia, the raw material for the production of cast parts is scrap metal of nonferrous metals or "churks" of aluminum, or other non-ferrous metal, which are bought by the relevant smelters of this metal (more often scrap metal). The raw material is processed into a powder - a finished raw material for the casting process.

The injection molding process includes:

1) mixing metal powders with polymers such as wax and a polypropylene binder to form a mixture;

2) injecting the liquid material into the mold by casting machines; 
3) the molded part or "raw part" is cooled and pushed out of the mold;

4) removal of the binder by means of solvents, catalytic method or combination of methods.

The resulting part is brittle and porous (40 percent of the volume of "air"). The finishing processes of parts after casting vary greatly depending on what the final product is required. The most common option: the part is transferred to the agglomerate furnace in a protective atmosphere at a temperature close to the melting point of the material. To seal the particles using capillary forces. The high diffusion rate leads to shrinkage and thickening of the material.

In addition, the difference in injection molding processes is due to the variety of alloys from which castings are made. Along with zinc, magnesium and aluminum alloys, widely used in production, alloys of copper, iron, titanium, heat-resistant alloys are increasingly being used. Special conditions for filling the mold with melt, which include evacuation and oxygen blowing, are also introduced into the technological processes.

There are several different injection molding technologies. The variety of injection molding processes is primarily associated with different types of pressing chambers and the arrangement of the pressing mechanism relative to the mold in the machine. The most common technological processes are carried out on machines with hot and cold horizontal and vertical pressing chambers. Machines with a hot horizontal pressing chamber and machines of vertical layout are not widely used.

Injection molding is divided into high pressure casting (HPDC), injection molding (LPDC), injection molding, gravitational casting (GDC).

High-pressure casting (HPDC) is divided into two types: cold-cast or hot-cast. Almost most often, the third version of the heated form is also used: (warm). In this method, the desired temperature is maintained by means of thermoregulators which are connected directly to the mold.

HPDC is an important process in the production of large volumes and inexpensive components for automotive, household appliances and electronics.

\section{Advantages and disadvantages of injection molding technology}

Digital manufacturing is the concept of technological preparation of production in a single digital environment using the tools of planning, verification and modeling of production processes, the so-called Industry 4.0 [8-9]. The CPU involves a single information space and end-to-end automation of all production processes, which is possible due to the translation of all information about the product, production processes and operation into digital form, that is, a parallel product creation chain is created, in other words, a digital twin of the enterprise and the product is created.

For example, using specialized CAE systems (AFS, SIMTEC, ProCAST, NovaFlow, PowerCAST, CastCAE) [10] allows you to visualize the injection molding process. Due to this, it is possible to identify various defects and deformations, residual stresses, determine volumetric and linear shrinkage, optimize casting and solidification modes, and, based on the results of the visualization, make adjustments at the stage of designing the casting design and process, which will significantly reduce the percentage of scrap, and therefore, there will be significant savings in metal, working time and electricity.

Automation of injection molding [11] provides increased resistance of mold parts and pressing chamber due to stable thermal conditions and regular lubrication of working and friction surfaces, improving surface quality and density of castings by regulating and stabilizing the thermal condition and lubrication of the mold and the pressing chamber; reducing losses due to metal burning, increasing productivity due to combining several operations in a casting cycle; reduced costs of muscular energy of the foundry and increased safety of its operation. 
Automation of injection molding is a multifaceted and difficult task. Depending on the specific production conditions, the quality of castings is managed at three different levels. In order to ideally follow the given process and the corresponding quality of the part, it is necessary to simultaneously monitor all three levels of control of the injection molding process with an instant reaction when detecting deviations taking into account the influence of the parameter of one level on another.

\section{Conclusions}

The most accurate machine-building workpieces are obtained by the injection molding method, its main advantages are the possibility of obtaining workpieces with minimum allowances for mechanical treatment or without it and minimum roughness of unprocessed surfaces, ensuring high productivity and low labor input of making parts, mainly from alloys based on zinc and aluminum. The main parameters affecting the filling and casting process are: the pressure on the metal during filling and underpressure, the pressing speed, the design of the runner-ventilation system, the temperature of the poured alloy, lubrication and vacuumizing modes.

The presence of the digital twin of the casting section will allow real-time monitoring of readings of sensors whose data are in a single information space from the casting machine installed in the pressing chamber, the mold, on manipulators designed to pour metal and extract the casting. This will allow an analysis of the injection molding process and quality control of castings, which will provide an opportunity to carry out an automated correction of the casting process modes without stopping production.

\section{References}

[1] T. Kovalyova, E. Eremin, S. Arinova, I. Medvedeva, A. Dostayeva, Enhancing surface roughness of castings when sand-resign mold casting, Metallurgy. 1-2 (2017) 135-138.

[2] N.V. Nemchinova, A.A. Tyutrin, Metallographic study of samples of aluminum rhondoles, Basic research. 3 (2015) 124-128.

[3] A.N. Romashkin, V.S. Oak, I.A. Ivanov, S.I. Markov, A.N. Malginov, D.S. Tolstoy, Development of a through technological process for the production of blanks for mechanical engineering based on compute-tert modeling, Metallurg. 9 (2014) 109-117.

[4] Additive technologies: 3D printing capabilities and perspectives, Pro-work. 2 (2017) 38-44.

[5] G. Singh, A. Verma, A. Verma, A Brief Review on injection moulding manufacturing process, Materials Today: Proceedings. 4 (2017) 1423-1433.

https://doi.org/10.1016/j.matpr.2017.01.164

[6] B. Pratap, R.K. Gupta, A. Yadav, M. Nag, Plastic injection molding and its process parameters, AIP Conference Proceedings. 2273 (2020) 050053.

https://doi.org/10.1063/5.0024291

[7] S. Tripathia, C. Mittermayrb, D. Muhra, H. Jodlbauera, Large scale predictability analysis of process variables from injection molding machines, Procedia Computer Science. 180 (2021) 545-560. https://doi.org/10.1016/j.procs.2021.01.274

[8] D.A. Kurasov, Computer-aided manufacturing: Industry 4.0, IOP Conference Series: Materials Science and Engineering. 1047 (2021) 012153. https://doi.org/10.1088/1757899X/1047/1/012153

[9] D.A. Kurasov, Digital technologies Industry 4.0, CEUR Workshop Proceedings. 2843 (2021).

[10] CAD \& Graphics log [Electronic Resource]. Access mode: http://sapr.ru/, swb. [11] N.A. Spirin, V.V. Lavrov, Information technologies in metallurgy. (2004) 495. 